\title{
Lower Sample Volumes Collected Into Spray-Dried K2EDTA Vacuitaner Bottles Are Suitable For Automated Complete Blood Count Analysis Including Differential Leukocyte Count
}

\author{
Fasakin $\mathrm{KA}^{1}$, Omisakin $\mathrm{CT}^{1}$,Esan $\mathrm{AJ}^{1}$ and Ajayi $\mathrm{OD}^{2}$ \\ Institutional Affiliations \\ 1. Department of Haematology, Federal Medical Centre, Nigeria. \\ 2. Department of Haematology, Obafemi Awolowo University Teaching Hospitals Complex, Nigeria.
}

\begin{abstract}
Collection of lower sample volumes into dipotassium ethylenediaminetetraacetic acid (K2EDTA) containers, according to the manufacturers' data and current Clinical and Laboratory Standards Institute, results in erroneous haematology results. To proof this we collected acceptable limit of lower sample volumes for haematology analyses into the $4.0 \mathrm{ml}$ standard spray-dried K2EDTA. $9.0 \mathrm{ml}$ of blood from 15 retroviral volunteers was collected and each donation was aliquot into the following volumes 4.0, 2.0, 1.5, 1.0, 0.5ml. These samples were analyzed within 4hrs of collection on Sysmex KX-21N haematology analyzer for complete blood count (CBC) including leukocytes differentials. T-test showed there was no significant difference between results of lower samples volumes and the standard volume and regression analysis showed excellent correlation for all parameters. Lower sample collection volumes compared to the standard volume showed negative bias for platelet count but the difference was considered insignificant with percentage differences of $4.6 \%, 3.0 \%, 2.9 \%$, and $1.7 \%$ for 1.0, 1.5, 0.5, and $2.0 \mathrm{ml}$ collection volumes respectively. Flag messages were noticed in about $67.0 \%$ of the patients irrespective of collection volumes. Acceptable CBC values for spray-dried K2EDTA collection tubes containing lower sample volumes can be obtained with as little as $1.0 \mathrm{ml}$ in Nigerian subjects.
\end{abstract}

Key words: CBC, Ethylenediaminetetraacetic acid, Macrocytes, Neutropenia, Relative lymphocytosis

\section{Introduction}

Proper specimen collection is the first step in ensuring accurate and reliable result from clinical laboratory. Incorrect anticoagulant: sample volume ratio has been identified as one of the pre-analytical factors that are responsible for non-reproducible haematology analyses especially complete blood counts (CBC) including leukocyte differential counts. ${ }^{1}$ According to recent Clinical and Laboratory Standard Institute document, procedure for the handling and processing of blood specimens, the amount of additives placed into a tube is intended for a certain volume of blood. If less than the required blood volume is drawn, the excess amount of additives has the potential to adversely affect the accuracy of test result. ${ }^{2}$

Another Clinical and Laboratory Standard Institute document, tubes and additives for venous blood specimen collection, also states that, "At the expiration date, the draw volume shall be no more than $10 \%$ below the stated draw volume of the manufacturer. ${ }^{3}$ Both standards are applied to all samples containers with different anticoagulants including ethylene diamine tetra-acetic acid (EDTA). It is important that the manufacturer instructions are precisely followed so as to ensure maximum and minimum allowable fill volumes and correct anticoagulant to specimen volume ratio.

\subsection{Historical Milestones In Complete Blood Count Analysis}

Prior to 1990, blood samples were collected into glass tube containing liquid K3EDTA as an anticoagulant for complete blood count analysis including differential leukocyte count in most clinical laboratories but still in use in most underdeveloped and some developing countries in Africa such as in most of our tertiary health institutions here.

In 1993, International Council for Standardization in Haematology in her Expert Panel for Cytometry document recommended the use of spray-dried K2EDTA as anticoagulant of choice for blood cell counting and sizing and has since then gained popularity in clinical laboratories that place value on conformity to standards. ${ }^{4}$ The same was approved for use by the Clinical and Laboratory Standards Institute in her standard guidelines for blood collection tubes and additives for venous blood specimen collection. For safety reason K2EDTA tubes began to replace glass tube as preferred blood collection containers.

Early 2000s, Becton Dickinson (BD, Franklin Lakes, NJ,USA) began to replace glass tubes as preferred blood collection containers. Van Cott $e t$ al in a study compared the newly produced spray-dried K2EDTA vacuitaner bottles with liquid K3EDTA glass tubes and found no clinically significant differences between these two types of containers for full blood count ran on automated haematology analyzers for the 
following parameters: WBC, RBC, platelets (Plt), haemoglobin (Hb), Haematocrit (Hct), mean cell volume (MCV) mean cell haemoglobin (MCH), mean cell haemoglobin concentration (MCHC), red cell distribution width (RDW), reticulocytes and WBC differentials including neutrophils(neut), lymphocyte(lymph), monocytes(mono),eosinophils (eos), and basophils (baso), as well as instrument flagging rate. Selected parameters (WBC, RBC, PLT, retics, Hb, MCV, MCHC, and RDW) had statistically significant differences, however they were small. The slight differences were attributed to the dilution effect of the liquid anticoagulant in glass tubes. ${ }^{5-6}$

Up to this time, there is no published data on the routine use of lower sample volumes in K2 EDTA collection tubes in Nigerian subjects. Previous CLSI guideline was based on the older studies on collection tubes with liquid anticoagulant. ${ }^{7-9}$ We hypothesized that the spraying of dry K2EDTA anticoagulant has drastically minimized haematological errors due to incorrect anticoagulant: blood volume ratio. Min \& co's findings on spray-dried K2EDTA in normal volunteers 2010 suggested that it was not necessary to completely fill spraydried K2EDTA blood collection tubes for haematological analyses. Their study was not carried out on pathologic samples and the haematology analyzer (Sysmex XE-2100) used is not common here as Sysmex KX$21 \mathrm{~N}$ is readily available in most Nigerian tertiary health institutions. We also hypothesized that if lower blood samples volumes collected into spray-dried K2EDTA could give complete blood count and leukocyte differential count results that compared well with the standard volume $(4 \mathrm{ml})$ in normal subjects, it should do the same in pathological conditions such as retroviral disease.

\subsection{Objectives of this Study}

We carried out this research

1. To proof our hypothesis that if lower blood samples volumes collected into spray-dried K2EDTA could give complete blood count and leukocyte differential count results that compared well with the standard volume $(4 \mathrm{ml})$ in normal subjects, it should do the same in pathological conditions such as retroviral disease.

2. To establish the suitability of Sysmex KX-21N analyzer to run full blood count samples collected into plastic, spray-dried K2EDTA containers using lower sample volumes.

3. To determine the minimum blood collection in volume that is required for complete blood count analysis and draw inferences as to the usefulness of this spray-dried additives containers for collecting neonatal, paediatric or geriatric samples especially where frequent sampling are required..$^{10}$

\subsection{Informed Consent Statement}

\section{Materials and Methods}

The participating volunteers after due pre-research counseling gave informed consent and were thus included in the research study. No personal bio-data was required.

\subsection{Sample collection}

The study was carried out over a period of six months. After obtaining informed consent as part of ethical consideration, 15 volunteers among our retroviral patients donated a total of $9.0 \mathrm{ml}$ of whole blood each collected by venepuncture into non anticoagulated syringe. Each $9.0 \mathrm{ml}$ blood volume collected was dispensed into five 4.oml vacuitaner blood collection tubes containing spray-dried K2EDTA in the following volumes: 4.0, $2.0,1.5,1.0$, and $0.5 \mathrm{ml}$.

\subsection{Sample Analysis}

The vacuitaner containers with different volumes of blood were analyzed for full blood count including leukocyte differential count (neutrophils, lymphocytes and mixed-sized cells) on an 18-parameter Sysmex KX$21 \mathrm{~N}$ haematology analyzer within four hours of collection integrating research samples with clinical samples during routine work. The mixed-sized cells represented eosinophils, monocytes and basophils). The results of the lower sample volumes $(0.5,1.0,1.5$ and 2.0$)$ were compared with the standard $4.0 \mathrm{ml}$ volume for clinically significant differences.

\subsection{Statistical Analysis}

For each of the CBC (including leukocyte differentials) parameters, the results from collection tubes with lower sample volumes were compared with the standard $4.0 \mathrm{ml}$ volume by comparison of means of paired sample using t-test. The mean value for each parameter was compared between lower sample volumes and the $4.0 \mathrm{ml}$ standard volume. The percentage difference of the mean was calculated for each of the parameter by first subtracting the mean for $4.0 \mathrm{ml}$ volume from that of the lower sample volume, then divided by the mean of the $4.0 \mathrm{ml}$ volume. To further proof the agreement of results between lower sample volumes and standard $4.0 \mathrm{ml}$ volume correlation and regression analysis were used to analyze samples from SPSS statistical software.

\section{Results}


The range for each of the FBC parameters including leukocyte differential parameter from 15 retroviral patients volunteers for $4.0 \mathrm{ml}$ collection volume are as follows: WBC $2.5-6.4 \times 10^{9} / \mathrm{L}$; RBC $2.50-4.81 \times 10^{12} / \mathrm{L}$; HGB 9.6-15.4g/dL; HCT 27.3-46.1\% MCV 85.6-111.8fL; MCH 26.8-39.50 Pg; MCHC 31.5-43.6g/dL; Plt 116-

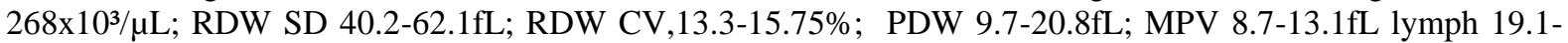

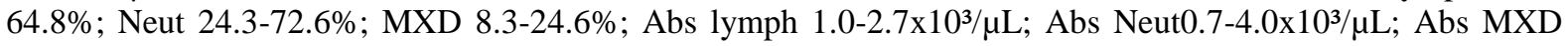
$0.3-0.5 \times 10^{3} / \mu \mathrm{L}$.

TABLE 1: Mean of all Parameters from 15 Samples for Each Collection Volume and Percentage Difference of Mean between Four Under-filled Volumes and Standard Volume. For example, the percentage difference for $1.0 \mathrm{ml}=($ mean of $4.0 \mathrm{ml}-$ mean of $1.0 \mathrm{ml} / \mathrm{mean}$ of $4.0 \mathrm{ml}) \times 100$

\begin{tabular}{|c|c|c|c|c|c|}
\hline COLLECTION & \multicolumn{5}{|c|}{ COMPARISON OF MEAN } \\
\hline VOLUME & 0.5 & 1.0 & 1.5 & 2.0 & 4.0 \\
\hline WBC (X103) & 4.4 & 4.5 & 4.4 & 4.5 & 4.4 \\
\hline $\mathrm{RBC}\left(\mathrm{X} 10^{12} / \mathrm{L}\right)$ & 4.0 & 3.8 & 3.8 & 3.7 & 3.8 \\
\hline $\mathrm{HGB}(\mathrm{g} / \mathrm{dL})$ & 12.2 & 12.2 & 12.1 & 12.0 & 12.2 \\
\hline $\operatorname{HCT}(\%)$ & 34.5 & 36.1 & 36.1 & 35.9 & 36.5 \\
\hline $\mathrm{MCV}(\mathrm{FL})$ & 92.0 & 96.6 & 96.6 & 96.5 & 96.7 \\
\hline $\mathrm{MCH}(\mathrm{pg})$ & 32.7 & 32.5 & 32.5 & 32.5 & 32.5 \\
\hline $\mathrm{MCHC}(\mathrm{g} / \mathrm{dL})$ & 33.7 & 33.6 & 33.6 & 33.8 & 33.6 \\
\hline $\operatorname{Plt}\left(\times 10^{9} / \mathrm{L}\right)$ & 180.2 & 177.0 & 180.0 & 182.5 & 185.6 \\
\hline RDW SD (fL) & 51.1 & 51.1 & 51.3 & 51.5 & 51.3 \\
\hline RDW & 4.7 & 14.6 & 14.6 & 14.7 & 14.7 \\
\hline PDW (fL) & 13.6 & 13.5 & 13.4 & 13.6 & 13.0 \\
\hline MPV (dL) & 10.4 & 10.5 & 10.4 & 10.5 & 10.3 \\
\hline $\operatorname{Lym}(\%)$ & 45.3 & 46.1 & 46.2 & 46 & .146 .3 \\
\hline Neut (\%) & 43.1 & 42.5 & 42.3 & 42.4 & 42.8 \\
\hline $\operatorname{MXD}(\%)$ & 11.6 & 11.5 & 11.4 & 11.3 & 311.0 \\
\hline Abs Lym $\left(x 10^{3} / \mu \mathrm{L}\right)$ & 1.9 & 2.0 & 2.0 & 2.0 & 2.0 \\
\hline Abs Neut $\left(\times 10^{3} / \mu \mathrm{L}\right)$ & 2.0 & 2.0 & 2.0 & 2.0 & 2.0 \\
\hline Abs MXD $\left(x 10^{3} / \mu \mathrm{L}\right)$ & 0.5 & 0.5 & 0.5 & 0.5 & 0.5 \\
\hline
\end{tabular}

$\begin{array}{cccc}\text { \% DIFFERENCE OF MEAN } \\ 0.5 & 1.0 & 1.5 & 2.0 \\ 0.0 & 2.3 & 0.0 & 2.3 \\ 5.2 & 0.0 & 0.0 & 2.3 \\ 0.0 & 0.0 & -0.8 & -1.7 \\ -5.5 & -1.1 & -1.1 & 1.1 \\ -4.9 & 0.1 & -0.1 & 0.2 \\ 0.6 & 0.0 & 0.0 & 0.0 \\ 0.3 & 0.0 & 0.0 & 0.6 \\ -2.9 & -4.6 & -3.0 & -1.7 \\ 0.4 & -0.6 & 0.0 & 0.4 \\ -0.7 & -1.4 & -1.4 & -0.7 \\ 4.6 & 3.8 & 3.1 & 4.6 \\ 1.0 & 2.0 & 1.0 & 2.0 \\ -2.2 & -0.4 & -0.2 & -0.4 \\ 0.7 & -1.2 & -1.2 & -0.9 \\ 5.5 & 4.5 & 3.6 & 2.7 \\ -5.5 & 0.0 & 0.0 & 0.0 \\ 0.0 & 0.0 & 0.0 & 0.0 \\ 0.0 & 0.0 & 0.0 & 0.0\end{array}$

WBC, white blood cell; RBC, red blood cell; HGB, haemoglobin; HCT haematocrit; MCV, mean cell volume; MCH, mean cell haemoglobin; MCHC, mean cell haemoglobin concentration; PIt, Platelet; RDW SD, Red cell distribution width standard deviation; RDW CV, Red cell distribution width coefficient of variation; PDW, Platelet distribution width; MPV, mean platelet volume; Lym, lymphocyte, Neut, neutrophils; MXD, mixed cell size; Abs, Absolute.

For all the parameters the percentage differences between the lower samples volumes compared to the standard volume were insignificant.

To compare whether there was significant difference between paired samples, we used correlation- regression analysis. TABLE 2 shows the result of our findings.

Table 2: Correlation and Regression Analysis Comparing CBC Results (including WBC differentials) Between Different Volumes of Blood Collection and 0.4ml Standard Volume

$\begin{array}{ccccccccccccc}\text { Volume } & \text { Slope/R } & \text { WBC } & \text { RBC } & \text { HGB } & \text { HCT } & \text { MCV } & \text { MCH } & \text { MCHC } & \text { PLT } & \text { LYM(\%) } & \text { NEUT(\%) } \\ 0.5 \mathrm{ml} & \text { slope } & 0.985 & 0.996 & 0.993 & 0.994 & 0.998 & 0.991 & 0.622 & 0.872 & 0.987 & 0.984 \\ & \mathrm{R}^{2} & 0.970 & 0.992 & 0.986 & 0.988 & 0.996 & 0.981 & 0.387 & 0.760 & 0.975 & 0.966 \\ 1.0 \mathrm{ml} & \text { slope } & 0.991 & 0.999 & 0.998 & 0.997 & 0.998 & 0.997 & 0.636 & 0.911 & 0.994 & 0.988 \\ & \mathrm{R}^{2} & 0.982 & 0.998 & 0.996 & 0.994 & 0.996 & 0.994 & 0.404 & 0.830 & 0.989 & 0.976 \\ 1.5 \mathrm{ml} & \text { slope } & 0.995 & 0.999 & 0.998 & 0.996 & 0.999 & 0.998 & 0.640 & 0.982 & 0.994 & 0.990 \\ & \mathrm{R}^{2} & 0.991 & 0.998 & 0.996 & 0.993 & 0.999 & 0.997 & 0.420 & 0.965 & 0.989 & 0.981 \\ 2.0 \mathrm{ml} & \text { slope } & 0.991 & 0.998 & 0.999 & 0.994 & 0.998 & 0.995 & 0.651 & 0.976 & 0.996 & 0.990 \\ & \mathrm{R}^{2} & 0.982 & 0.997 & 0.998 & 0.988 & 0.997 & 0.991 & 0.432 & 0.953 & 0.992 & 0.981\end{array}$




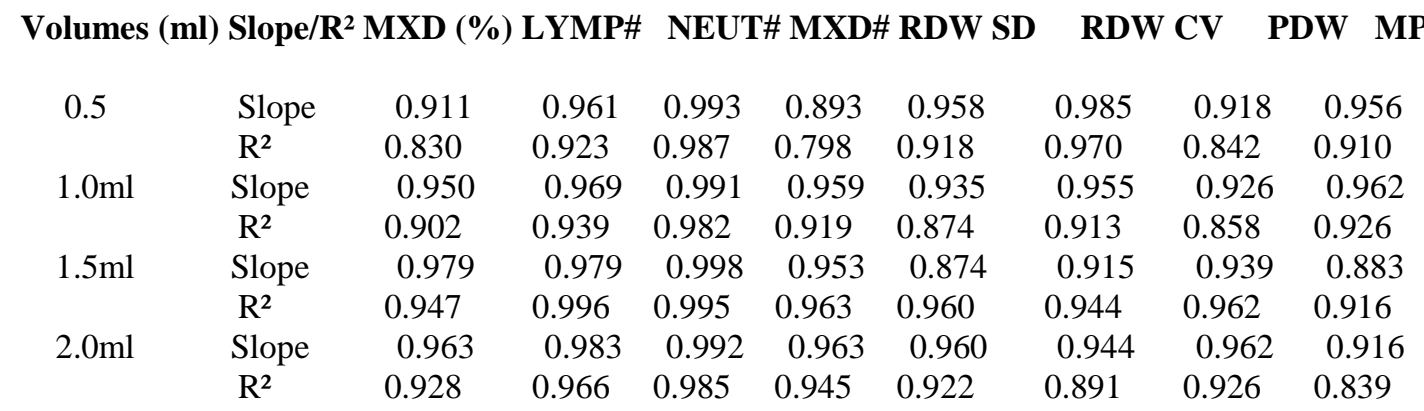

WBC, white blood cells; RBC, red blood cells; HGB, haemoglobin; HCT, haematocrit; MCV; mean cell volume; MCH, mean cell haemoglobin; MCHC, mean cell haemoglobin concentration; PLT platelet; LYM, lymphocyte; NEUT, neutrophils; \% percent MXD, mixed size cells; \#, absolute; RDW, red cell distribution width; SD, standard deviation; CV, coefficient of variation; PDW, platelet distribution width; MPV mean platelet volume.

All parameters with the exception of mean cell haemoglobin concentration showed excellent correlation between different low sample volumes compared to the standard volume. Both slope and $\mathrm{R}^{2}$ were between 0.8 and 1.0 for almost all the parameters except

i. $\quad 0.5 \mathrm{ml}$ volume for MXD\# (Slope, $0.893 ; \mathrm{R}^{2}, 0.798$ )

ii. Both $0.5 \mathrm{ml}$ for Plt (slope, $0.918 ; \mathrm{R}^{2}, 0.760$ )

The correlation of MCHC was sub-optimal for all the four lower sample volumes with the $0.5 \mathrm{ml}$ volume having the lowest slope and $\mathrm{R}^{2}$ values (Slope.0.622; $\mathrm{R}^{2}, 0.387$ ). The mechanism behind this still remains unclear. Unlike Min and his colleagues who experiment this same hypothesis in normal volunteers, we used pathological conditions for our research. There is no clinically significant difference between these lower sample volumes and the $4.0 \mathrm{ml}$ standard volume. The platelet count seems to have a negative bias for all the four lower sample volumes. We considered the difference as clinically insignificant since the average percentage difference was just $4.6 \%, 3.0 \%, 2.9 \%$ and $1.7 \%$ for $1.0,1.5,0.5$ and $2.0 \mathrm{ml}$ respectively. The underline mechanism for this negative bias still remains unclear.

\subsection{Flag Message Analyses}

We also analyzed the difference for flagged messages produced by the automated analyzer. Since these are pathological samples, it is interesting to note that though flagged messages occurred, they were noted in all blood collection volumes except in few cases. That is, there was no flag messages difference between samples collected into $4.0 \mathrm{ml}$ standard volume and the lower sample collection volumes $(2.0 \mathrm{ml}, 1.5 \mathrm{ml}, 1.0 \mathrm{ml}$ and $0.5 \mathrm{ml})$. The first ten $(66.7 \%)$ set of samples run had flag messages irrespective of sample volumes. Some of these findings flagged by the Sysmex KX-21N (Sysmex Corporation, Kobe, Japan) automated instrument are normal findings in Nigeria subjects. The first patient had "relative lymphocytosis and neutropenia and abnormal red cell distribution' flag messages irrespective of sample collection volumes. Second volunteer had 'leucopenia, neutropenia and relative lymphocytosis' flag message which also cut across all samples volumes. The third patient volunteer had abnormal red cell and platelet distribution width' flag messages. The same patient also had MCV (112fL) and MCH (40pg) flag message suggestive of megaloblastic anaemia which might be due to possible dietary vitamin B12 or foliate deficiency or liver deterioration or dysfunction. Peripheral blood film examination revealed anisocytosis, hypochromia, macrocytes and few target cells. The HGB for this patient was $11.7 \mathrm{~g} / \mathrm{dL}$. The flag messages were noted irrespective of sample volumes. The fourth volunteer only had negative flag message on MCV parameter. The standard $4.0 \mathrm{ml}$ volume had mean MCV of $85.6 \mathrm{fL}$ while lower sample volumes MCV were between 83.6 and $86.1 \mathrm{fL}$. These values are still normal findings in apparently healthy Nigerian subjects. The fifth volunteer had anaemia. All her red cell indices were within normal range. Normal reference range for Nigerian subjects for red cell indices are: MCV, 80-100fl; $\mathrm{MCH}, 27-32 \mathrm{pg}$, and MCHC, 32$36 \mathrm{~g} / \mathrm{dL}$. ${ }^{1 T}$ This cut across all sample volumes. Peripheral blood film examination showed anaemia of the normocytic normochomic type which is a classic finding in chronic disease such as retroviral disease. ${ }^{12-13}$ Neutropenia and lymphocytosis flag messages were noted in sixth volunteer. This is a common findings among retroviral patients not yet placed on ART because of possible intact immune status. There was no report of haematological symptoms such as mouth ulcers due to neutropenia in the patient. Seventh to tenth volunteer had similar flag message across all sample volumes which were observed differences between American and 
Nigerian subjects. The rest 5 research volunteers had no flag message showing relatively normal haematological values and normal peripheral blood film examination.

\section{Discussion}

We are currently using K3EDTA collection tubes for barely all our patients except on occasional cases where we have supply from supporting HIV/AIDS implementing partners. Experience has shown various disadvantages are associated with this collection tubes which significantly affect patient and staff safety, and testing efficiency and as well as reproducibility of results. First, often times, we need to reject samples that are lower than the required volume in this collection tubes necessitating another draw for the patient; secondly, the issue of incorrect anticoagulant: blood volume ratio makes it difficult when drawing blood from neonatal, pediatrics and geriatric patients especially when such patients need follow-up. Thirdly, where testing procedures require that different samples be collected for test, several volumes of blood will be needed for the analyses which, in practice, may not be feasible in a number of patients. Besides, repeated large volume blood draw from hospitalized patients have been shown to cause hospital-induced anemia. ${ }^{14}$ Our results of CBC haematology parameters ran on Sysmex KX-21N compared well with those of Min $\mathrm{Xu}^{6}$ and his colleagues who researched the use of lower sample volumes in American normal volunteers using Sysmex XE-2000 automation instrument. For all the parameters with the exception of MCHC the slope and $\mathrm{R}^{2}$ values were between 0.8 and 1.0. Most of the values were between 0.9 and 1.0. Our research provided additional information of sub-optimal MCHC correlation-regression statistical values in lower sample collection volumes in standard 4.0ml spray-dried K2 EDTA vacuitaner bottles in pathological subjects. The slope and $\mathrm{R}^{2}$ values were highest in $2.0 \mathrm{ml}$ and lowest in $0.5 \mathrm{ml}$ collection volume. Slope and $\mathrm{R}^{2}$ values were also lower in $0.5 \mathrm{ml}$ collection volume for platelet and mixed sized cells parameters compared to $2.0,1.5$ and $1.0 \mathrm{ml}$ lower sample volumes. This creates some reasons for caution in using uncontrolled lower collection volumes in standard $4.0 \mathrm{ml}$ collection tubes. In advanced countries where the use of capillary blood in microtainer tubes especially in neonatal and pediatrics cases have been alternative means overcoming the charge of having to collect large volumes, the tubes are now gradually being replaced with spray-dried K2EDTA for similar reasons and cost effectiveness. If lower sample volumes can be drawn into standard $4.0 \mathrm{ml}$ container, only one size collection tubes needs to be stocked for our use in the haematology laboratory and various wards which will be more cost effective. Our research findings clearly showed that there is no clinically significant difference although some samples are statistically significant for selected few full blood count parameters and leukocyte differentials. There are no variations in instrument flagging rates noted with lower sample volumes collected into $4.0 \mathrm{ml}$ blood collection tubes. Interestingly, Sysmex KX-21N analyzer requires only $50 \mu 1$ of whole blood for automated sampling mode, and for pre-dilution mode only $20 \mu \mathrm{l}$ of blood is required thus permitting repeat test from the $1.0 \mathrm{ml}$ sample drawn if need be. Our study complements that by Min and his colleagues (2010) and provides answer to limitations that might have been associated with the study such as use of normal subjects only and single analyzer as we used pathological specimens and a different analyzer.

\section{Conflict of interest}

The authors state that no conflict of interest is declared.

\section{Conclusion}

On the basis of our research findings, collecting a minimum of $1.0 \mathrm{ml}$ of whole blood into $4.0 \mathrm{ml}$ lavender top tube has no significant effect on routine $\mathrm{CBC}$ analysis including leukocyte differentials especially when run on Sysmex KX-21N hematology analyzer. Standardizing to one $4.0 \mathrm{ml}$ spray- dried K2EDTA tube for vast majority of patients would reduce re-collection of samples (which particularly will be of benefits to neonatal, paediatric and geriatric patients who often require frequent testing), simplify testing process, improve staff safety and reduce inventory and supply cost. We could not get more than 15 patients enrolled for the study owing to several volumes of blood that needed to be collected for research CBC analysis besides other routine baseline tests required for newly diagnosed HIV patients initiation on antiretroviral therapy. More research involving the use of other analyzers apart from Sysmex series are also necessary to corroborate our findings. Haematology department in various secondary and tertiary health institutions in the country should begin to replace liquid K3EDTA containers with spray-dried K2 EDTA vacuitaner blood collection tubes. Plastic spraydried K2EDTA collection tubes is recommended as this prevent onset of coagulation process(unlike the glass type) and sample volume variation do not significantly affect haematology values. Well-planned inventory and ordering is paramount to prevent stock-out and compulsory reverse to old practice and approval of the containers should be ensured before use as specimen bottles for haematology analyses 


\section{Acknowledgement}

The findings in this research article are the sole responsibilities of the participating authors. We would like to thank Mr. Ogunbiyi Oluwaseun and Adeyemi Adesina for their contributions on statistical analysis of this work and our interns who also played important roles in the cost of this research.

\section{References}

[1] Anne Stiene Raymond L.O (1998). Specimen collection for haematology: principles, procedures and correlations, $2^{\text {nd }}$ Eds, pp 9-10, 1998.

[2] Clinical and laboratory standards institute (CLSI). (2004). Procedures for the handling and processing of blood specimens. Approved guideline- Third edition.H18-A3, 24 (21).

[3] Clinical and laboratory Standard Institute (CLSI, 2003). Tubes and additives for venous blood specimen collection. Approval guideline-fifth edition. HI-A5, 16(13), 5.

[4] The International Council for Standardization in Haematology: Expert Panel for Cytometry. Recommendations of the International Council for Standardization in Haematology for ethylene diamine tetra acetic acid anticoagulant of blood for blood cell counting and sizing. Am J Clin Path. 1993; 100:371-372.

[5] Van Cott E.M., Lewandrowski K.B., Patel S., Grzybek D.Y and Kratz A. (2003) comparison of glass K3EDTA versus plastic K2EDTA blood drawing tubes for complete blood counts, reticulocyte count, and white blood cell differentials. Laboratory Haematology 9, 10-14.

[6] Min Xи A., Robbe VA, Jack RM, Ruthledge JC (2010).Under-filled blood collection tubes K2EDTA as anticoagulant are acceptable for automated complete blood counts, white blood cell differential, and reticulocyte count. International journal of Laboratory Haematology, 32,491-497.

[7] Lampasso J.A. (1965). Error in haematocrit value procedure by excessive ethylene-diamine tetra acetic acid. American Journal of Clinical Pathology: 44,109-110.

[8] Sacker L.S. (1975) specimen collection in quality control in haematology (Eds S.M. Lewis and J.F Coster), PP.224-227. Academic Press, New York.

[9] Lewis S.M. \& Stoddart C.T.H.(1977) effects of anticoagulants and containers (glass and plastic) on blood count. Lab Practice 20, 787-792.

[10] Sanchez-Giron F. \& Alvarez-mora F.(2008) Reduction of blood loss from laboratory testing in hospitalized patients using smallvolume (paediatric) tubes. Archive of pathology and laboratory medicine 132, 1916-1919.

[11] Erhabor O, Isah A, Isaac IZ and Udomah FP (2013). Iron deficiency anaemia among antenatal women in Sokoto, Nigeria. Br J Health Sci. 1(4): 47-57.

[12] WKBA Owiredu, L Quaye, N Amidu, and O Addai-Mensah (2011. Prevalence of anemia and immunological markers among Ghanaian in HAART-nä̈ve and those on HAART. Afr Health Sci. v11 (1); March, 2011.

[13] Arindam Pande, Maitreyee Bhattacharyya, Shantasil Pain, Ajanta Samanta (2011). Study of bone marrow changes in antiretroviral nä̈ve human immunodeficiency virus-infected anaemic patients. Indian J Pathol Microbiol (serial online) 2011; 54: 542-6.

[14] Paaladimesh Thavendiranathan, Akshay Baggai, Albert Ebidia, Allan S Detsky and Niteesh K Choudhry (2005). Do Blood Tests Cause Anemia in Hospitalized Patients? The Effects of Diagnostic Phlebotomy on Hemoglobin and Hematocrit Levels. J Gen Intern Med.2005; 20 (6): 520-524. 